\title{
Research on the Path of "New Agriscience" Talents Cultivation Under the Background of Rural Revitalization
}

\author{
Yuanhong Wang,* Xiaoqiong Wang, Yi Liu
}

\author{
Tianjin Agricultural University, 300384, Tianjin, China \\ *Corresponding author. Email: mubi86485@foxmail.com
}

\begin{abstract}
On the basis of studying the connotation of Rural Revitalization Strategy, the dilemma of talent training and development, and the orientation of new agricultural talent training, this paper discusses how to train new agricultural talents in local agricultural colleges and universities. Through literature review, investigation and analysis, the author believes that the core idea of new agricultural talent training is to cultivate new agricultural talents with modern university concept and innovative features. The path of new agricultural talent training is to promote discipline integration, consolidate the knowledge structure of "thick foundation and wide caliber", guide cooperation and exchange, and build a practice platform of "strong practice and innovation", we will strengthen social services and implement a testing mechanism of "wide adaptation and high quality".
\end{abstract}

Keywords: New agriculture, Rural revitalization, Talents cultivation.

\section{INTRODUCTION}

Both the report of the 19th CPC National Congress and the Fifth Plenary session of the 19th CPC Central Committee emphasized the strategy of rejuvenating the country through science and education, the strategy of strengthening the country with talents and the strategy of innovation-driven development, the state should improve the innovation system and promote the development of science and technology, Sustainable development, and rural revitalization, the state should promote the comprehensive green transformation of economic and social development and consolidating the achievements of poverty alleviation. These arrangements put forward new requirements for the development of higher education," Agriculture, rural areas and farmers ", which has injected new impetus and opportunities, and pointed out the direction of the reform of new agricultural education in colleges and universities in China. The construction of "New Agriscience" is the demand of education and teaching reform in agricultural colleges and universities in our country, which is the foundation of agricultural modernization development, and it is the guarantee of realizing rural rejuvenation. "Taking demand as traction and breaking through bottlenecks is the leading direction of agricultural education and agricultural science and technology. That is imperative which we have to explore and solve the bottleneck of traditional agricultural development actively, to integrate new knowledge, skills and culture, to integrate and create new knowledge system, and to create new agricultural forms. Facing the international frontier of agricultural science and technology, national development and new goals of social and economic development, we should build a discipline system that meets the needs of the development of "Agriculture, rural areas and farmers ". It is requires highlighting innovation urgently, interdisciplinary development, paying attention to applied research and basic research, providing scientific and technological support from a single industrial chain to the whole industrial chain. We should promote the transformation from single industrial chain to whole industrial chain, and the transformation from single discipline to interdisciplinary, so as to promote the deep integration of primary, secondary and tertiary industries. 


\section{THE DEMAND FOR THE GOAL OF RURAL REVITALIZATION IN NEW AGRICULTURAL TALENTS}

\subsection{The Connotation of the Talent Revitalization in the Rural Revitalization Strategy}

In the three industrial revolutions before, human beings completed "mechanization", "electrification" and "automation" respectively. Now, we are heading for the fourth industrial revolution, developing from the digital revolution and stepping into the "intelligent era"[1]. At this special time, China has put forward the goal of "two hundred years "and actively implemented the five development concepts of" innovation, coordination, green, development and sharing ". The country should actively realize rural revitalization. From the perspective of the evolution of international rural construction, the countryside is the short board of national comprehensive strength development and it is a necessary stage to make up for this short board. In the last century, the United States, Britain, the Netherlands, France, Japan, Japan South Korea and so on, they have promoted each characteristic countryside development practice. By contrast, the development of rural areas in China should formulate agricultural land policies according to regional types, strengthen the process of three industrial integration and urban-rural integration, establish and protect brands with local characteristics, persist in developing ecologically friendly, modern and specialized agriculture, promote the construction of new "professional" farmers[2], and strengthen the ability of rural governance. In the strategy of rural revitalization, talents are the guarantee premise, foundation and core, which is the source of rural governance culture and the foundation of Rural Endogenous Development [3]. Talent revitalization is the foundation for the four revitalization which include industry revitalization, culture revitalization, ecology revitalization and organization revitalization. Rural revitalization requires the aggregation of farmers, governments, returning talents, technical experts, entrepreneurs and entrepreneurs and other groups, which covers law, management, transportation, education, energy, ecology and many other fields. The primary task of Rural Revitalization is to cultivate a work team who understand agriculture, love the countryside and love farmers. It meets the needs of rural development, and it can actively participate in the construction of rural areas, and combine knowledge with practice, so as to create power for modern agriculture and rural development. Higher agricultural education, should cultivate college students' simple feelings in rural construction, as well as the ability to display their talents in rural areas. They can not only be competent for rural grass-roots work in an all-round way, but also have the comprehensive quality, theoretical and practical skills of positive innovation and entrepreneurship, and become the new force to drive the development of rural areas.

\subsection{The Personnel Training and Development Dilemma in the Rural Revitalization Strategy}

China's rural governance is facing a variety of challenges, such as the loss of human resources, capital inflow and outflow, changes OF land policy are impacting the development and governance of rural areas. On the one hand, the elite of the countryside itself, such as the youth of migrant workers and college students, are constantly flowing out, the rural talents stationed in the countryside are difficult to open up a new situation of rural revitalization. The development of industry, culture, ecology and organization is weak and difficult, various factors restrict each other. On the other hand, before the special policy guidance and tilt, the rural work and living environment is difficult, the social identity is low, the livelihood is difficult, the local employing unit personnel system is not perfect, therefore university Students are still unwilling to study agriculture and engage in agricultural related work. Due to the influence of the hard work characteristics of agriculture itself, social change, social distribution mechanism and other historical factors, the agricultural development of our country is relatively lagging behind, the added value of production technology and agricultural products lags behind the level of developed countries, and the salary and post prospect are not enough to absorb the existing agricultural college students that employment situation of Agricultural College Students is difficult. At the same time, in addition to the consideration of livelihood and survival factors, Agricultural Colleges and universities personnel training accuracy, scientificity, adaptability deviation, lack of coordination between agricultural specialty setting and industrial institutions. The graduates of agricultural majors have narrow knowledge, insufficient self-study ability, insufficient theoretical depth of professional knowledge and production practice skills, which makes it difficult for them to make contributions to rural development rapidly. For the teaching and discipline construction of agriculture related higher education in our country, there are many pain points of breakthrough, such as deviation of professional orientation, confusion and high subdivision of discipline and professional education, lack of understanding of the importance of "based on undergraduate education" and professional education ${ }^{[4]}$, lack of mechanism to respond quickly to the new situation; obvious boundary of discipline, weak dominant discipline, interdisciplinary integration, leading or combining with the deficiency of modern science and technology, of the separation between agricultural science and social science ${ }^{[5]}$. The lack of "imparting knowledge and solving doubts" is insufficient, and knowledge teaching is more than 
exploratory guidance etc. The mission of higher agricultural education is to meet the new demand of "high efficiency, product safety, resource saving and environment-friendly" in agricultural and rural areas, to reposition the discipline construction of "New Agriscience", develop specialty and correct the deviation in personnel training.

\subsection{The Orientation of New Agricultural Talents Training in the Rural Revitalization Strategy}

China's agricultural development has experienced a succession of 1.0 to 3.0. Every scientific and technological change has led to the change of agricultural production. With the development of Internet technology in the new era, China's agricultural station is at the crossroad to meet 4.0, and an intelligent, accurate, social and mechanized agricultural era is expected. At the same time, a multi-dimensional and unified large-scale system which pays attention to the conservation of ecological resources and environmental friendliness can be expected in the future. Since the 19th century, the concept of general education has been widely accepted by the developed countries, and has been gradually adapted to the development of general education in the world. In contrast, the contribution rate of China's higher education to agricultural development, the combination with agriculture related industries, interdisciplinary integration and talent training structure layout have greater room for improvement. China's agriculture is also facing severe challenges, mainly manifested in the accelerated aging of labor force after the loss of rural human resources, the lack of competitiveness of agricultural product breeding technology, the decline of international competitiveness of products, the rise of various production costs, the pressure of ecological environment, and the low degree of agricultural production organization and marketization [7]. China's agriculture is also facing severe challenges, mainly manifested in the accelerated aging of labor force after the loss of rural human resources, the lack of competitiveness of agricultural product breeding technology, the decline of international competitiveness of products, the rise of various production costs, the pressure of ecological environment, and the low degree of agricultural production organization and marketization. According to Liu Zhuqing of China Agricultural University that the "New Agriscience" is to solve the new opportunities and challenges of China's agricultural and rural modernization which can promote the strategy of innovation-driven development and the strategy of strengthening higher education, promote the deep intersection and integration of agricultural disciplines and other disciplines, expand the new connotation of traditional agricultural disciplines, construct or optimize the new mode of running higher agricultural education and educating people, train modern agricultural talents with broad vision, thick scientific foundation, wide knowledge structure, high comprehensive quality and strong innovation ability, enhance the international competitiveness of Chinese higher agricultural education, and provide important supporting for the realization of the great rejuvenation of the Chinese nation Chinese Dream ${ }^{[6]}$.

\section{TO STRUCTURE THE CORE CONCEPT OF TRAINING MODE OF NEW AGRICULTURAL TALENTS IN LOCAL AGRICULTURAL COLLEGES AND UNIVERSITIES}

\subsection{Training New Agricultural Talents with Modern University Concept}

The concept of modern university pays more attention to the cultivation of innovative quality of talents to meet the requirements of the new era. It not only pays attention to the cultivation of technical personnel with broad professional background ${ }^{[8]}$, but also realizes the multiple unity of humanistic spirit, scientific spirit and innovative spirit of students, cultivates all-round development and healthy personality of social people, and cultivates learners with the will of continuous learning and lifelong learning. The setting of specialties in local agricultural colleges and universities still continues the tradition, and there are still gaps and contradictions between the talent training mode and the quality standards and the concept of modern universities. From the existing personnel training system, the specialty setting is narrow, the content of the course has not covered the results of scientific research, the teaching methods can not follow the optimal education law, not meet the diverse development needs of students, and the proportion of incentive students' endogenous learning motivation is insufficient. Therefore, the existing personnel training system can not reflect the subjectivity and selectivity of talent development, and it is difficult to realize the effective unity of talents' interest, specialty and occupation. In terms of the quality of personnel training, in recent years, the talent training objectives and teaching concepts have become more and more clear. The requirements of colleges and universities for the cultivation of talents with comprehensive development of morality, intelligence, physique, beauty and labor are much more clear, which is in line with the concept of modern universities, but there is still a long way to go.

\subsection{Training New Agricultural Talents with innovative characteristics}

Innovative talents refer to those who have a strong sense of innovation, innovative spirit and innovation abilities, can carry out creative work and make 
contributions to the society. They are the first resources driven by national innovation. The construction of the four new disciplines (i.e. new liberal arts, new engineering, new agriculture, and new medicine) is in itself in response to the demand and call of innovation and Reform in the new era. New agricultural talents are to creatively transform and integrate traditional agriculture with their innovative quality, characteristics, ability and broad knowledge. From the spirit of Anji consensus, Beidacang action and Beijing Guide, the national standards of undergraduate teaching quality and the national certification standards have put forward new specific requirements for talent cultivation. The new agricultural education is to cultivate the comprehensive characteristics of innovative thinking, skills and ability, as well as broad and broad agricultural knowledge background talents who have a strong passion for innovative methods or affairs, and have a strong will. They also have a wide range of humanistic cultivation, and have a tough character ${ }^{[9]}$.

\section{TRAINING PATH OF NEW AGRICULTURAL TALENTS IN LOCAL AGRICULTURAL UNIVERSITIES}

Local agricultural colleges and universities should establish new agricultural talents training path based on their own characteristics.

\subsection{Promote the Integration of Disciplines and Consolidate the Knowledge Structure of Thick Foundation and Wide Caliber}

Higher agricultural education in China has the tendency of homogenization. The development foundation and service regions of local colleges and universities are different, which promotes or restricts the characteristic development of local colleges and universities. Local agricultural colleges and universities should not only face the development of regional agricultural economy, but also face the agricultural industry of the whole country. At the same time, they should take the integration of disciplines as the path to consolidate students' knowledge structure of thick foundation and wide caliber. Standing at the forefront of the times, agriculture 4.0 must be integrated with the technology of digital revolution. The development of "New Agriscience" must actively seek changes, meet the new of digital revolution and create the "intelligent era" of agriculture. The cultivation of talents in Colleges and universities should take the initiative to seek change and new spirit, and break the barriers of thinking, disciplines, industry and technology, and change the traditional knowledge structure of single discipline group to the combination of knowledge population of multi-disciplinary group, and cultivate talents with thick foundation and wide caliber knowledge structure and professional background. Agriculture related industries have their special basic, productive and regional attributes. The development of "New Agriscience" requires higher agricultural education to grasp the development context of agricultural and rural modernization, follow this law, discover emerging disciplines and interdisciplinary subjects, strengthen the integration and penetration of traditional disciplines, constantly expand, and enrich the cornerstone of talent cultivation.

\subsection{Guide Cooperation and Exchange, Build Strong Practice, Emphasis on Innovation Practice Platform}

The government, colleges and universities, teachers, students and society are the main body to promote teaching reform. In terms of the background of the current double first-class construction and the four new constructions, the government and colleges and universities have taken active action, teachers and students need to strengthen guidance, and the society has great potential to explore. At present, the present situation of classroom teaching in colleges and universities is worrying, some classroom teaching methods are still old, teaching content emphasizes knowledge but ignores ability and innovation, the teaching subject lacks vitality, and the teaching effect is not satisfactory ${ }^{[10]}$. The productive nature of agriculture requires higher agricultural education to follow the law of agricultural production, and it is urgent to strengthen production and practice, and to build a practical teaching system and platform that is coordinated with production practice. The construction of local colleges and universities depends on the development of the local, the foundation is different, and the practice resources are relatively insufficient. Therefore, it is urgent to explore social forces and build a practice platform jointly built by various societies and enterprises. In terms of policy guidance and encouragement, teachers and students in different disciplines and specialties should be encouraged to cooperate widely in teaching discussion and scientific research projects, and carry out diversified practical exploration and innovation.

\subsection{Strengthen Social Services and Implement the Inspection Mechanism of wide adaptation and high quality}

Once, the teaching concept that takes the teaching as the center and the development of subject simplification, the research and teaching of agricultural teachers are far away from the land and production practice. Today's reform concept that takes the learning as the center requires teachers to learn by themselves, demonstrate by themselves, drive students to learn, cultivate students' comprehensive ability and quality, and finally serve the society. Local agricultural and forestry colleges and 
universities must be aware of their own advantages and disadvantages, promote the supply side innovation of higher agricultural education, and explore the cultivation of high-level agricultural talents with characteristics. Social service is not only the teachers and students in Colleges and universities to contribute their wisdom, but also in the process of serving the society, to find out the window to understand the society, to find the needs of society, so as to cultivate talents with social needs. At the same time of strengthening social services, we should build a testing mechanism of "wide adaptability and high quality" for new agricultural talents.

\section{CONCLUSIONS}

In the new era, the Rural Revitalization strategy must first be supported by talent revitalization. In the face of new development needs and challenges, there are some difficulties in the previous talent training model. On the basis of clarifying the orientation of new agricultural talents training, the core idea of constructing new agricultural talents training in local agricultural universities is to cultivate new agricultural talents with modern university ideas and innovative characteristics. Local agricultural colleges and universities should not only face the development of regional agricultural economy, but also face the national agricultural industry, actively promote the integration of disciplines, consolidate the knowledge structure of "thick foundation and wide caliber", widely guide cooperation and exchange, build a practice platform of "strong practice and innovation", strengthen social services, and implement the inspection mechanism of "wide adaptation and high quality", Broaden the training path of training new agricultural talents in local agricultural colleges and universities.

\section{ACNKOWLEDGMENTS}

Fund Project 1: phased achievement of "exploration and practice of new agricultural talents training mode with innovation and entrepreneurship as the core" of education and teaching reform project of Tianjin Agricultural University in 2018, Project No.: 2018-a-01.

Fund Project 2: phased achievement of "research and practice on the curriculum construction of Chinese traditional culture - taking flower art as an example" of education and teaching reform project of Tianjin Agricultural University in 2021, Project No.: 2021-A-18.

Corresponding author: Wang Yuanhong (1974 -), male, Han nationality, Dean of horticulture and Landscape Architecture College of Tianjin Agricultural University, Professor, doctor, mainly engaged in biological control of plant diseases and teaching management.

\section{REFERENCES}

[1] Dong Weichun, Liang Chenchen, Liu Xiaoguang. Higher agricultural education from tradition to modernization--proposal for china's New-Agriculture [J]. Chinese agricultural history, 2018, 37 (06): 33-45

[2] Guo Xiaoran, Zhou Li, Yu Hu, Wu Dianting, Xu Linlin. The evolution and effect analysis of Japan's rural revitalization policy $[\mathrm{J}]$. World geographic research, 2020, 29 (05): 905-916

[3] Tan JinFang, Zhang Chaoyang, sun Yufeng, Li Shumin. System construction of rural talents cultivation in agricultural universities under the background of rural revitalization strategy [J]. China agricultural education, 2018 (06): 17-22 + 93

[4] Wang Xiaoqiong, Wang Yuanhong. Dilemma and Enlightenment of professional education development in applied agricultural colleges and universities in the new era $[\mathrm{J}]$. Contemporary education practice and teaching research, 2020 (05): 110-111

[5] Liu Zhuqing. On the Development Strategy of “ New Agriscience" in the Generational Changes of Agriculture $[\mathrm{J}]$. China agricultural education, 2018 (01): $15-21+92$

[6] Chen Xiwen. Agricultural development situation and challenges in China [J]. Rural economy, 2015 (1): 3-7

[7] Ji Hui. Analysis and Thinking on the Training of Agricultural Talents in Agricultural Universities [J]. Anhui Agricultural Science, 2020, 48 (18): $264-266+268$

[8] Guo Mingshun. Reconsideration on training goal of undergraduates from the view of the university's idea [J]. Higher education research, 2008, 29 (12): 84-88

[9] Gao Daocai, Zhang Lixin. Research on the innovation quality and training path of "NewAgricultural Science" talents [J]. Higher agricultural education, 2020 (01): 51-55

[10] Liu Zhentian. Classroom teaching revolution in Colleges and Universities: reality, essence and Realization [J]. Higher education research, 2020, 41 (07): 58-69 